\title{
Profiles of polychlorinated biphenyls (PCBs) in cement kilns co-processing solid waste
}

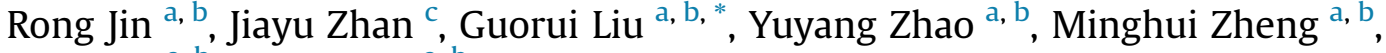 \\ Lili Yang ${ }^{\mathrm{a}, \mathrm{b}}$, Mei Wang ${ }^{\text {a, b }}$ \\ a State Key Laboratory of Environmental Chemistry and Ecotoxicology, Research Center for Eco-Environmental Sciences, Chinese Academy of Sciences, \\ Beijing 100085, China \\ ${ }^{\mathrm{b}}$ University of Chinese Academy of Sciences, Beijing 100049, China \\ ' State Key Laboratory of Solid Waste Reuse for Building Materials, Beijing Building Materials Academy of Sciences Research, Beijing 100041, China
}

\section{H I G H L I G H T S}

- Variations of PCBs within cement kilns co-processing solid waste were evaluated.

- Kiln end area and cyclone preheater were dominant sites of PCB formation.

- Tetra-to hexa-chlorinated biphenyls were dominant PCB homologues.

- Co-processing of waste in cement kilns did not increase PCB emissions.

\section{A R T I C L E I N F O}

\section{Article history:}

Received 17 September 2016

Received in revised form

17 January 2017

Accepted 23 January 2017

Available online 24 January 2017

Handling Editor: Caroline Gaus

\section{Keywords:}

Cement kiln

Co-incineration

Polychlorinated biphenyl

Persistent organic pollutants

Sewage sludge

\begin{abstract}
A B S T R A C T
Co-incineration of sewage sludge in cement kilns can be used for its disposal. In the present study, samples were collected from three cement production runs where sewage sludge and other wastes (e.g. municipal solid waste, waste acid and wet sewage sludge) were co-processed. The samples were analyzed for polychlorinated biphenyls (PCBs). The dioxin-like ( $\mathrm{dl}$ )-PCB concentrations in the stack gases from run 1, 2, and 3 were $344.6,548.7$, and $104.3 \mathrm{pg} \mathrm{m}^{-3}$, respectively. The toxic equivalency (TEQs)

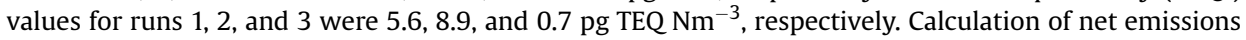
for the three runs indicated that the co-incineration of other waste in addition to sewage sludge in cement kilns would not increase emission of the dl-PCBs. PCB concentrations in samples from the suspension boiler and humidifier tower, kiln-end bag filter, and cyclone preheater were much higher than those in samples from the kiln head area, indicating that these stages will be important for controlling PCB formation. Chlorinated biphenyl (CB)-77, CB-105 and CB-118 were the major dl-PCB congeners, $\mathrm{CB}-52, \mathrm{CB}-101$ were the major indicator $\mathrm{PCB}$ congeners, and tetra- $\mathrm{CB}$ to hexa-CB were the major homologues for the total input or output materials.
\end{abstract}

(c) 2017 Elsevier Ltd. All rights reserved.

\section{Introduction}

Sewage sludge is a residue that is generated during water treatment. Among the available sewage sludge disposal strategies, thermal processes are considered the most useful for reducing the mass, volume, and organic pollutant content of sewage sludge

\footnotetext{
* Corresponding author. State Key Laboratory of Environmental Chemistry and Ecotoxicology, Research Center for Eco-Environmental Sciences, Chinese Academy of Sciences, Beijing 100085, China.

E-mail address: grliu@rcees.ac.cn (G. Liu).
}

(Werle and Wilk, 2010). One of thermal processes is co-incineration of sewage sludge in cement kilns, and this method has been studied previously (Conesa et al., 2008; Schuhmacher et al., 2009; Rovira et al., 2011; Aranda Usón et al., 2013; Rivera-Austrui et al., 2014). The benefits of disposing of sewage sludge in cement kilns have been discussed (Werle and Wilk, 2010; Aranda Usón et al., 2013). Due to the toxicity and persistence of persistent organic pollutants (POPs), the formation and emission of unintentionally produced POPs from this thermal process are of increasing public concern. Therefore, studies on the behavior of POPs during cement kiln coprocessing of sewage sludge are needed.

Polychlorinated dibenzo-p-dioxins and dibenzofurans (PCDD/ 
Fs) and POP precursors, including polycyclic aromatic hydrocarbons (PAHs) and polychlorinated benzenes, are emitted when sewage sludge is co-incinerated in a cement kiln (Harrison et al., 2006; Conesa et al., 2008; Rivera-Austrui et al., 2014). The effects of the PCDD/Fs generated during co-incineration of sewage sludge in cement kilns on the environment and human health have been comprehensively evaluated (Schuhmacher et al., 2009; Rovira et al., 2011). However, previous studies on cement kiln co-processing of waste have mainly focused on PCDD/Fs and PAHs, and few studies have investigated changes in polychlorinated biphenyls (PCBs) in cement kilns, even though these chemicals are harmful to human health and the environment (Ahlborg et al., 1992; Safe, 1993; Giesy and Kannan, 1998; Conesa et al., 2008, 2011; Nomiyama et al., 2014).

In a similar manner to PAHs and polychlorinated benzenes, PCBs will partition onto sewage sludge during wastewater treatment because they are lipophilic (Blanchard et al., 2004; Guo et al., 2009; Ozcan et al., 2013). This means that sewage sludge introduced to a thermal process will contain PCBs and precursors for the formation of PCBs (Weber et al., 2001; Pekárek et al., 2007; Jiang et al., 2015). The existing of PCBs and PAHs in the sewage sludge have been identified by previous studies. For example, Guo et al. reported PCB concentrations ranging from 65.6 to $157 \mathrm{ng} \mathrm{g}^{-1}$ dry weight (dw) in sewage sludge samples from eight urban wastewater treatment plants (Guo et al., 2009). Blanchard et al. reported PAH concentrations ranging from 14 to $31 \mathrm{mg} \mathrm{kg}^{-1} \mathrm{dw}$, and PCB concentrations ranging from 0.07 to $0.65 \mathrm{mg} \mathrm{kg}^{-1} \mathrm{dw}$ in sludge from storage chambers (Blanchard et al., 2004). Besides that, the cooling processes after high temperature burning would have the potential to form PCBs (Jansson and Andersson, 2012; Tuan et al., 2012). Unintentional emission from industrial thermal processes is a major source of atmospheric PCBs (Liu et al., 2013). Earlier studies on emission of POPs from industrial thermal processes have shown that PCBs are emitted at the same time as PCDD/Fs and behave in a similar manner (Liu et al., 2009; Hu et al., 2013). Therefore, PCBs could form during co-processing of sewage sludge in cement kilns. Consequently, more studies on PCB formation and distribution within cement kilns during co-processing are needed.

To the best of our knowledge, however, there has been only one study on the emission of PCBs from sewage sludge co-incineration in a cement kiln (Rivera-Austrui et al., 2014). This study mainly focused on the levels of PCBs emitted from the kilns, and did not investigate how PCB formation varied in the different stages of the process. There are several stages in a cement kiln process, and each uses different operating conditions, which would affect PCB formations and degradations (Zhang et al., 2014; Dang et al., 2015; Jiang et al., 2015). Few studies were performed to analyze the variations of PCBs among the different stages of a cement kiln when co-processing sewage sludge. The investigation on the PCB variations from different stages of cement kiln co-processing sewage sludge could provide new knowledge for recognizing the dominant stages of PCB formations during the cement kiln co-processing sewage sludge.

In this study, stack gas and solid samples were collected from different stages of cement kilns during three separate runs of waste co-processing. Dried sewage sludge was the main waste coprocessed in all three runs, and was the only waste processed in one of the runs. In the other two runs, other wastes were also processed in addition to the dried sewage sludge, including municipal solid waste (MSW) in one run, and waste acid and wet sewage sludge in the other. The aims of this study were as follows: (1) to clarify how PCBs are distributed at different process stages within cement kilns; (2) to identify the major sites for PCB formation within cement kilns; and (3) to demonstrate the congener and homologue profiles of PCBs from cement kiln co-processing solid waste. The results presented in this study will increase understanding of PCB behavior within kiln systems co-processing solid waste.

\section{Materials and methods}

\subsection{Information on the cement kilns co-processing of solid waste and sample collection}

Samples were collected from three waste co-processing runs from two cement kilns, which were operated using the similar protocol. Each cement kiln contained a rotary kiln, a pre-calciner, cyclone preheaters, a humidifier tower, a suspension (SP) boiler, two bag filters (one at the kiln end and one at the kiln head), a cooler, a coal mill, a boiler at the kiln head, and a chimney. For each run, stack gas samples, and solid samples from the kiln-end bag filter (ck-s9), SP boiler and humidifier (ck-s8), C1 preheater (ck-s7), raw meal (ck-s5), coal (ck-s4), clinker (ck-s3), boiler at the kiln head (ck-s2), and bag filter at the kiln head (ck-s1) were collected. In run 3 , dried sewage sludge (ck-s6) was also collected. The techniques used in the three runs and the sampling sites are shown in Fig. 1, and were similar to those in a previous study (Jin et al., 2016).

The raw meal used in both Run 1 and Run 2 was from the same silo, and was a mixture of lime stone (87\%), sewage sludge (7\%), clay (1.5\%) and other materials. Raw meal was added to the cyclone preheater, and passed through the pre-calciner, rotary kiln, and cooler. The gaseous products of pyrolysis of the municipal solid waste (MSW) were also imported into the pre-calciner and coprocessed in the cement kiln in Run 2. The MSW had a combustible content of about $78 \%$ and was combusted in the incinerator at a rate of about 72,000 kg per day. For run 3, sewage sludge was imported separately to the raw meal. Dried sewage sludge $(338,000 \mathrm{~kg})$ was imported into the pre-calciner, $10,000 \mathrm{~kg}$ of waste acid was imported into the kiln head, and $38,000 \mathrm{~kg}$ of wet sewage sludge was added to the bottom of the pre-calciner. The flow rates for the stack gas, the masses of raw meal, masses of coals used, and masses of clinkers produced for the three runs are listed in Table 1. The solid lines represent the flow of solid materials, and the dotted lines represent the gas flows (Fig. 1). The fly ash from the kiln-end bag filter was recycled into the cyclone preheater with the raw meal.

\subsection{Analytical method of $P C B$ congeners}

The PCBs were analyzed using isotope dilution high-resolution

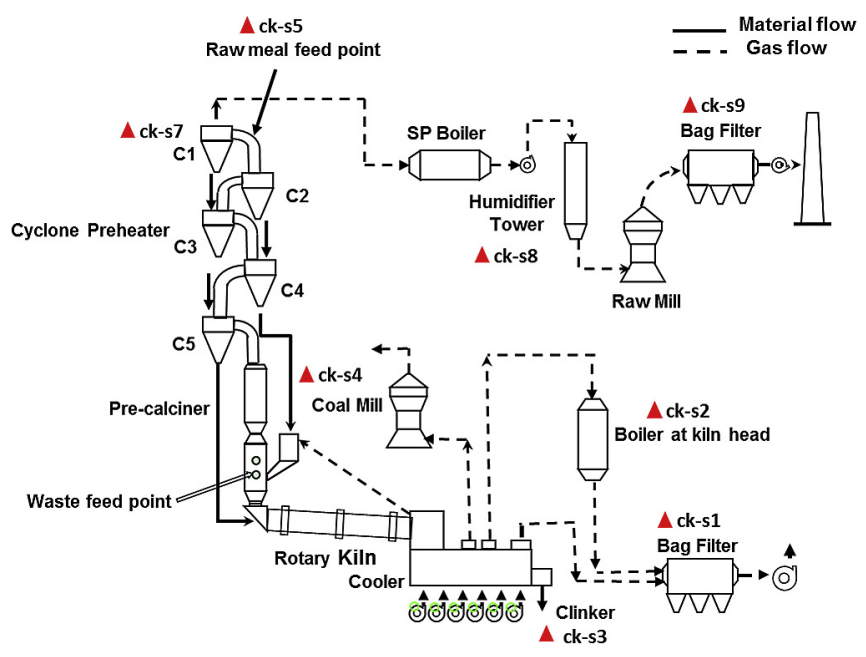

Fig. 1. Diagram of cement kiln production line. 
Table 1

PCB concentration and TEQs, and mass balance for the cement production system.

\begin{tabular}{|c|c|c|c|c|c|c|c|c|}
\hline Plant & Run & & $\begin{array}{l}\text { Flow rate } \\
\left(\mathrm{m}^{3} \mathrm{~h}^{-1}\right)\end{array}$ & $\begin{array}{l}\text { Amount } \\
\left(\mathrm{t} \mathrm{d}^{-1}\right)\end{array}$ & $\begin{array}{l}\text { dl-PCB (pg m }{ }^{-3} \\
\left.\text { or pg g }{ }^{-1}\right)\end{array}$ & 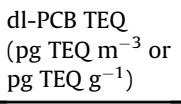 & Mass $\left(\mathrm{mg} \mathrm{d}^{-1}\right)$ & TEQ $\left(\mu \mathrm{g}\right.$ TEQ $\left.\mathrm{d}^{-1}\right)$ \\
\hline \multirow[t]{6}{*}{ Plant1 } & \multirow[t]{6}{*}{ Run1 } & Stack gas & \multirow[t]{6}{*}{251,424} & & 345 & 5.6 & 2.1 & 33.8 \\
\hline & & Raw meal & & 4880 & 623 & 4.3 & 3039 & 21,132 \\
\hline & & Coal & & 352 & 62.8 & 0.1 & 22.1 & 24.0 \\
\hline & & Clinker & & 3012 & 300 & 0.3 & 904 & 847 \\
\hline & & Net emission & & & & & -2155 & -20274 \\
\hline & & Reduction efficiency (\%) & & & & & 70.4 & 95.8 \\
\hline \multirow[t]{6}{*}{ Plant 1} & \multirow[t]{6}{*}{ Run2 } & Stack gas & \multirow[t]{6}{*}{227,828} & & 549 & 8.9 & 3.0 & 48.7 \\
\hline & & Raw meal & & 3386 & 623 & 4.2 & 2109 & 14,232 \\
\hline & & Coal & & 431 & 41.2 & 0.1 & 17.7 & 22.4 \\
\hline & & Clinker & & 2090 & 130 & 0.2 & 272 & 456 \\
\hline & & Net emission & & & & & -1851 & -13750 \\
\hline & & Reduction efficiency (\%) & & & & & 87.1 & 96.5 \\
\hline \multirow[t]{7}{*}{ Plant 2} & \multirow[t]{7}{*}{ Run3 } & Stack gas & \multirow[t]{7}{*}{221,476} & & 104 & 0.7 & 0.6 & 1.5 \\
\hline & & Sludge & & 338 & 426 & 0.4 & 144 & 138 \\
\hline & & Raw meal & & 4406 & 84.0 & 0.1 & 370 & 363 \\
\hline & & Coal & & 422 & 203 & 0.3 & 85.6 & 121 \\
\hline & & Clinker & & 2754 & 5.2 & 0.1 & 14.3 & 147 \\
\hline & & Net emission & & & & & -585 & -473 \\
\hline & & Reduction efficiency (\%) & & & & & 97.5 & 76.1 \\
\hline
\end{tabular}

gas chromatography and high resolution mass spectrometry (HRGC-HRMS) using EPA method 1668B, which is described in previous studies (Liu et al., 2009; Lv et al., 2011). Each stack gas sample or solid sample was spiked with a mixture of ${ }^{13} \mathrm{C}_{12}$-labeled PCB internal standards (1668-LCS; Cambridge Isotope Laboratories, Andover, MA). The solid samples were digested by hydrochloric acid, washed with distilled water until they reached $\mathrm{pH} 7$, and freeze-dried. Then, the solid samples and stack gas samples were extracted with toluene for more than $20 \mathrm{~h}$. Each extract was cleaned using a series of chromatography columns, including a multilayer silica gel column and an activated carbon column. The cleaned extract was concentrated to about $50 \mu \mathrm{L}$. The concentrated extract was injected with a mixture of ${ }^{13} \mathrm{C}_{12}$-labeled $\mathrm{PCB}$ recovery standards (1668A-IS; Cambridge Isotope Laboratories) for analysis by HRGC-HRMS. The PCBs analysis was performed using an Agilent 6890 gas chromatograph (Agilent Technologies, Santa Clara, CA), coupled with an Autospec Ultima high resolution mass spectrometer (Waters Micromass, Milford, MA). Separation was performed on a DB-5 MS fused silica column $(60 \mathrm{~m} \times 0.25 \mathrm{~mm} \times 0.25 \mu \mathrm{m}$, Agilent Technologies). The mass resolution was higher than 10,000.

\subsection{Quality control and quality assurance}

Recoveries of ${ }^{13} \mathrm{C}_{12}$-labeled PCB internal standards were in the range $39-127 \%$, which met the requirements of US EPA method 1668B. The detection limits were defined as three times the signalto-noise ratio. The detection limit ranges for the congeners were $0.02-0.8 \mathrm{pg} \mathrm{g}^{-1}$ for the solid samples and $0.2-2.3 \mathrm{pg} \mathrm{m}^{-3}$ for the stack gas samples. Blank experiments were carried out with each batch of the samples to confirm there was no obvious interferences for sample quantification.

\section{Results and discussion}

\subsection{Concentrations of dioxin-like ( $d l)-P C B s$ in samples from the cement kilns co-processing solid wastes}

The concentrations of dl-PCBs in samples of the stack gases, raw meals, coals, and clinkers collected from the three runs are listed in Table 1. The dl-PCB concentrations in the stack gas samples from run 1,2 , and 3 were 345,549 , and $104 \mathrm{pg} \mathrm{m}^{-3}$, respectively. Toxic
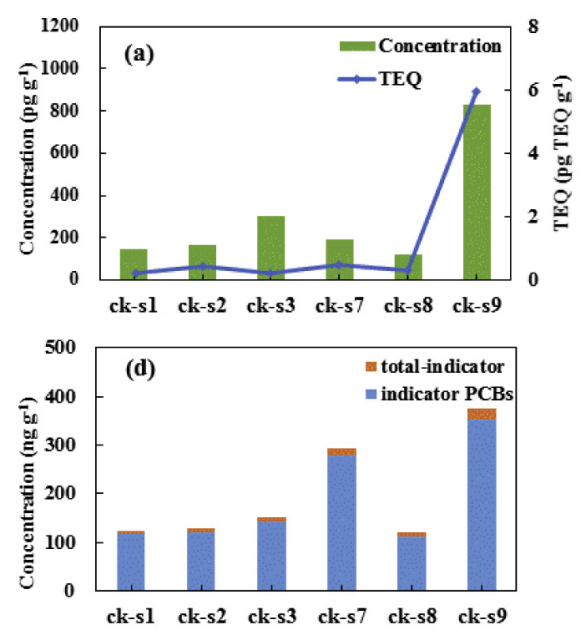
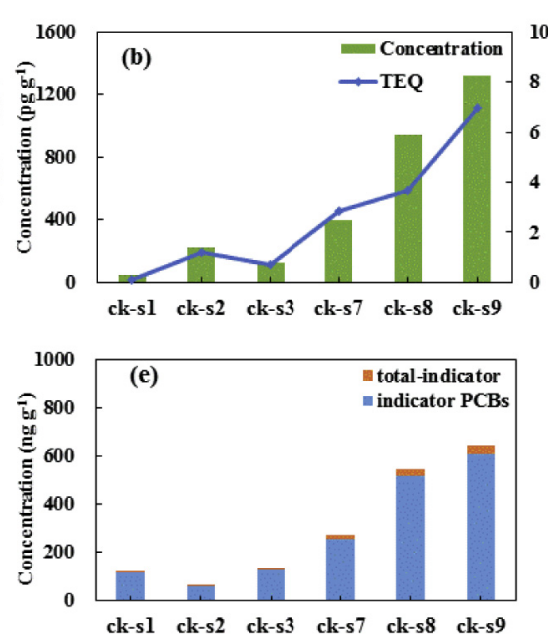
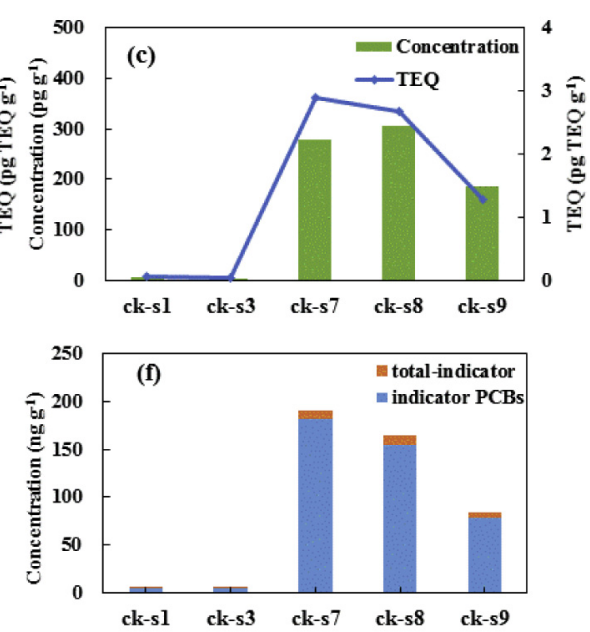

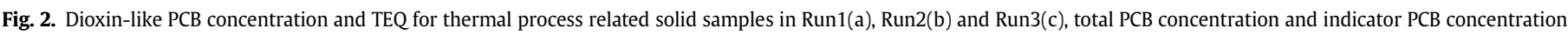
for thermal process related solid samples in Run1(d), Run2(e) and Run3(f). 

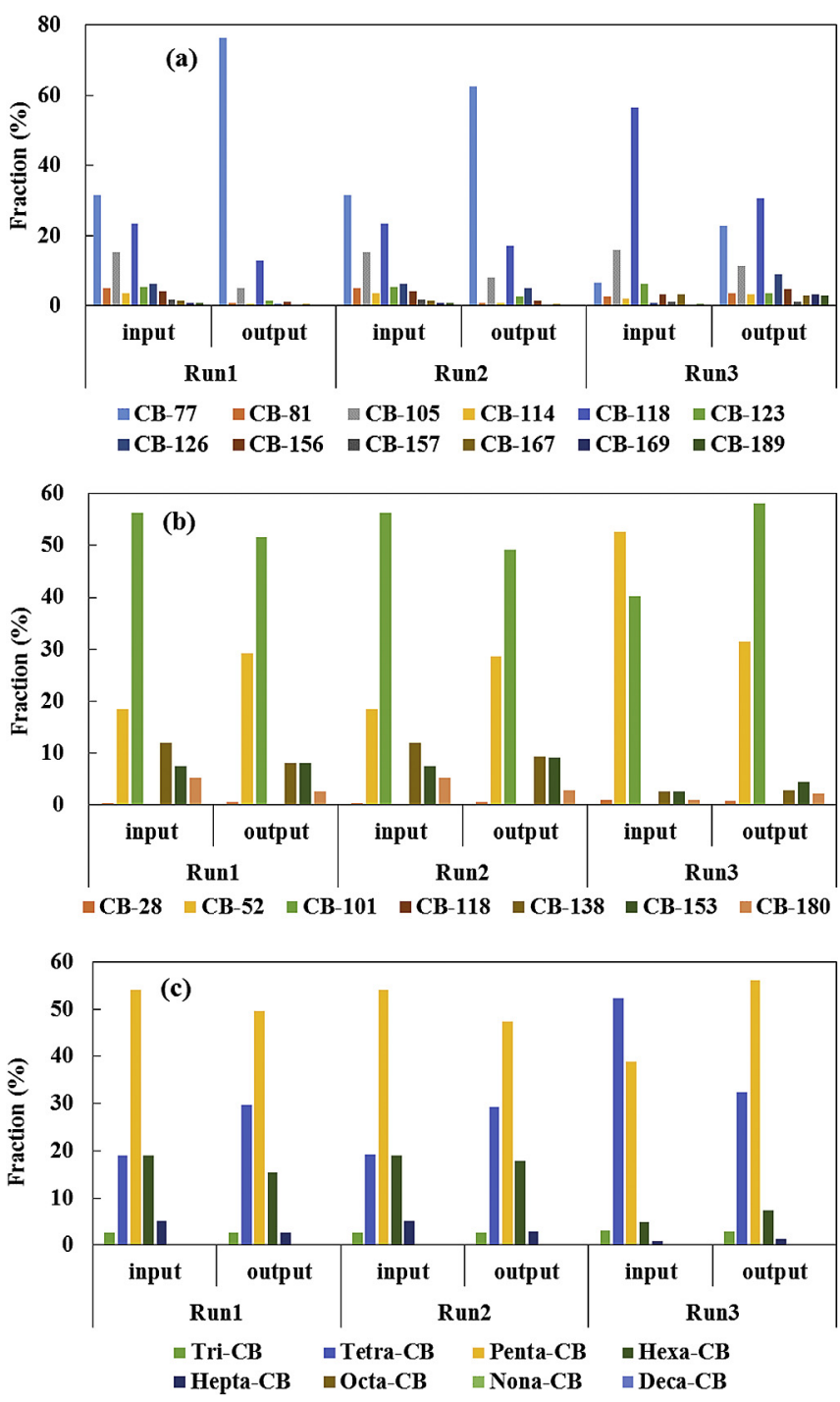

Fig. 3. Fractions for dioxin-like $P C B$ congeners (a), indicator $P C B$ congeners (b) and $P C B$ homologues (c) for input and output mass.

equivalencies (TEQs) were calculated based on the toxicity equivalency factors assigned by the World Health Organization(Van den Berg et al., 2006). The TEQs for dl-PCBs in stack gas from run 1, 2, and 3 were $5.6,8.9$, and $0.7 \mathrm{pg} \mathrm{TEQ} \mathrm{Nm}^{-3}$, respectively. These values were all higher than the PCB TEQ (average 0.3 pg TEQ $\mathrm{Nm}^{-3}$ ) reported for stack gas from a cement kiln co-processing refuse derived fuel (RDF) and sewage sludge, but similar to that reported for PCBs in flue gas with no co-processing of waste (3.5 pg TEQ $\mathrm{Nm}^{-3}$ ) (Liu et al., 2011; Rivera-Austrui et al., 2014).

To evaluate the efficiency of PCB formation and destruction in cement kilns, mass balances were calculated based on the dl-PCB concentrations in the stack gas and solid samples, and the mass of each input or output item. The input and output masses of the PCBs were calculated by multiplying the PCB concentrations with the corresponding mass of each item. In the present study, cement kiln that was used to co-process the waste used a recycling system. This meant that fly ash generated in back-end bag filter during production was recycled back into the kiln system. The main PCB input sources included the raw meals, coals, and sewage sludge, and the main PCB output sources were the stack gas and clinkers.

In run 1 and 2, more than 99\% of the input dl-PCBs came from the raw meal. In Run 3, raw meal and dried sewage sludge accounted for about $85 \%$ of the dl-PCBs input. The proportion of $\mathrm{dl}-$ PCBs input from coals was higher in Run 3 than in Run 1 or Run 2. The distribution of PCB TEQs from the input sources were similar to the PCB mass distributions, with raw meals accounting for more than $99 \%$ of the input PCB TEQ in Run 1 and Run 2, and raw meal and dried sewage sludge accounting for about $81 \%$ in Run 3 . For the output sources of dl-PCBs, the dl-PCBs were mainly emitted from the kilns through clinkers, which accounted for more than $96 \%$ of the output dl-PCB mass and dl-PCB TEQ in the three runs.

The net emissions of dl-PCBs were calculated by subtracting the input PCB masses and TEQs from the output dl-PCBs masses and TEQs. For run 1, 2, and 3, the net emissions were $-2155,-1851$, and $-585 \mathrm{mg}$ per day, respectively. The TEQ emissions were $-20.3,-13.8$, and $-0.5 \mathrm{mg}$ TEQ per day for run 1,2 , and 3 , respectively. These indicated that the kiln system would not promote the emissions of dl-PCBs, but reduce the dl-PCB amounts. Mass reduction efficiencies were also calculated as the absolute value of net emissions divided by input mass. The reduction efficiencies for runs 1,2 , and 3 were $70.4 \%, 87.1 \%$, and $97.5 \%$, respectively. Based on these results, co-incineration of municipal solid waste in cement kilns will enhance the reduction efficiencies of PCBs. These results provide evidence to support conclusions from earlier studies that claimed that co-incineration of waste in cement kilns would not have a significant detrimental environmental impact compared to kilns not co-processing waste (Schuhmacher et al., 2009; Rovira et al., 2014).

\subsection{Variation of $P C B$ concentrations within the kiln systems co- processing solid wastes}

The concentrations of dl-PCBs, indicator PCBs, and total PCBs (from tri-to deca-chlorinated) in solid samples from the thermal processes within the kiln system were determined (Fig. 2). In this study, the ranges for the dl-PCB concentrations were 119-828 $\mathrm{pg} \mathrm{g}^{-1}, 46.1-1318 \mathrm{pg} \mathrm{g}^{-1}$, and 5.2-305 $\mathrm{pg} \mathrm{g}^{-1}$ for samples from Run 1, Run 2, and Run 3, respectively. The TEQs of PCBs in solid samples were $0.2-6.0 \mathrm{pg} \mathrm{TEQ} \mathrm{g}^{-1}$ for Run $1,0.1-7.0 \mathrm{pg} \mathrm{TEQ}^{-1}$ for

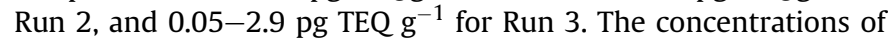
indicator PCBs and total PCBs were also determined (Fig. $2 d-f$ ). The indicator PCB concentration ranges were $112-352 \mathrm{ng} \mathrm{g}^{-1}$, 60.0-613 $\mathrm{ng} \mathrm{g}^{-1}$, and 4.8-182 $\mathrm{ng} \mathrm{g}^{-1}$ in solid samples from Run 1, Run 2, and Run 3, respectively. The total PCB concentration ranges were $119-374 \mathrm{ng} \mathrm{g}^{-1}, 64.1-62.2 \mathrm{ng} \mathrm{g}^{-1}$, and 5.2-191 $\mathrm{ng} \mathrm{g}^{-1}$ in samples from Run 1, Run 2, and Run 3, respectively. These results showed that more than $90 \%$ of the total PCBs were indicator PCBs.

Sewage sludge was co-processed in all three cement production runs. In addition, MSW was co-processed in Run 2, and waste acid and wet sewage sludge were co-processed in Run 3. Despite the differences in waste input, the variations in PCBs at different stages in the three runs were similar. Overall, the concentrations and TEQs of PCBs in samples from the kiln-end area (SP boiler and humidifier tower, and kiln-end bag filter) and C1 preheater were higher than in samples from the kiln-head area. This indicated that optimization of the operating conditions for stages at the kiln-end area and C1 preheater should be emphasized for inhibiting PCB formation. This is consistent with previous studies that reported high PCDD/F and PCN concentrations in samples from the SP boiler and humidifier tower, kiln-end bag filter, and C1 preheater (Liu et al., 2015, 2016; Jin et al., 2016).

The same raw meal was used in Run 1 and Run 2. A comparison between the two runs showed that the total PCB concentrations were similar in clinkers, in samples from the kiln-head, and from the $\mathrm{C} 1$ preheater. By contrast, in samples from the SP boiler and humidifier tower, and kiln-end bag filter, the total PCB concentrations were obviously higher in Run 2 (547 $\mathrm{ng} \mathrm{g}^{-1}$ and $642 \mathrm{ng} \mathrm{g}^{-1}$, 

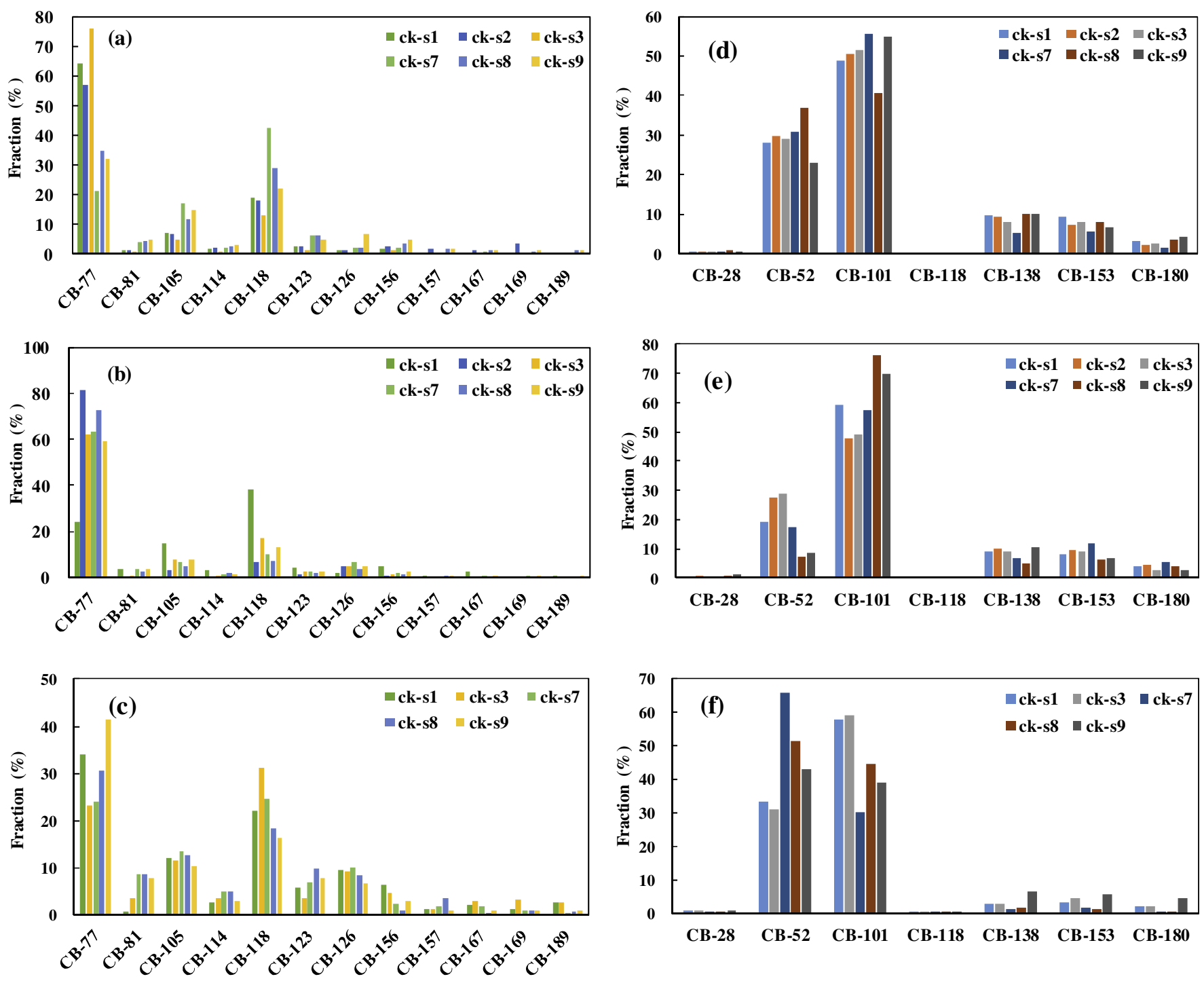

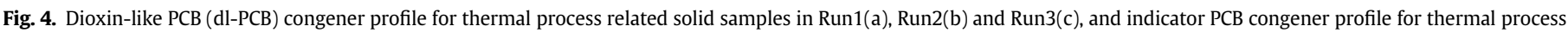
related solid samples in Run1(d), Run2(e) and Run3(f).

respectively) than in Run 1 (119 $\mathrm{ng} \mathrm{g}^{-1}$ and $374 \mathrm{ng} \mathrm{g}^{-1}$, respectively). This indicated that co-incineration of MSW might promote PCB formation at the kiln end. Ash from the kiln end is usually recycled back into the kiln system. Therefore, formation of PCBs at the kiln end should not greatly affect the PCB emissions.

\section{3. $P C B$ congener and homologue distributions in solid samples}

Analysis of the contributions of each dl-PCB congener to the $\sum$ dl-PCBs (Fig. 3a) showed that chlorinated biphenyl (CB)-77, CB105 , and CB-118 were the major PCB congeners in the input and output materials from the three runs. These results are consistent with previous studies on dl-PCBs from other kilns (Rivera-Austrui et al., 2014). However, there were some differences between the dl-PCB profiles for the input and output materials. From input to output, the fraction of CB-77 increased from $31.5 \%$ to $76.2 \%, 31.5 \%-$ $62.4 \%$, and $6.6 \%-22.9 \%$ in Run 1 , Run 2, and Run 3, respectively. By contrast the fraction of $\mathrm{CB}-105$ decreased from $15.3 \%$ to $5.1 \%$, $15.3 \%-8.1 \%$, and $15.9 \%-11.5 \%$ in Run 1 , Run 2, and Run 3, respectively. The fraction of CB-118 also decreased, from $23.6 \%$ to $13.0 \%$, $23.6 \%-17.1 \%$, and $56.6 \%-30.7 \%$ in Run 1, Run 2, and Run 3, respectively. These results indicate that the reduction efficiencies for CB-105 and CB-118 were higher than that for CB-77. The distributions of indicator PCBs in the input and output materials were analyzed (Fig. 3b). For all three runs, the dominant indicator PCB congeners in both the input materials and output materials were CB-52 and CB-101. The lowest fractions among the indicator congeners were observed for $\mathrm{CB}-28$ and $\mathrm{CB}-118$ for both the input and output materials for all three runs.

The PCB congener profiles for solid samples from the thermal processes within the kiln system (Fig. 4) showed similar congener distributions to the input and output materials, with CB-77, CB-105, and CB-118 as the major dl-PCB congeners, and PCB-52 and PCB101 as the major indicator $\mathrm{PCB}$ congeners in solid samples. The ranges for the fraction of CB-77 in the total dl-PCBs were $21.2 \%-$ $76.2 \%$ in Run $1,24.1 \%-81.3 \%$ in Run 2 , and $23.1 \%-41.5 \%$ in Run 3. The ranges for the fractions of CB-105 were $5.1 \%-17.3 \%, 3.3 \%-14.7 \%$, and $7.5 \%-13.5 \%$ in Run 1 , Run 2 , and Run 3, respectively. The ranges for the fractions of $\mathrm{CB}-118$ were $13.0 \%-42.5 \%, 6.6 \%-38.2 \%$, and $16.3 \%-31.2 \%$ in Run 1, Run 2, and Run 3, respectively. The contributions of CB-77 observed in solid samples in the present study were higher than those for other industrial samples reported by Liu 

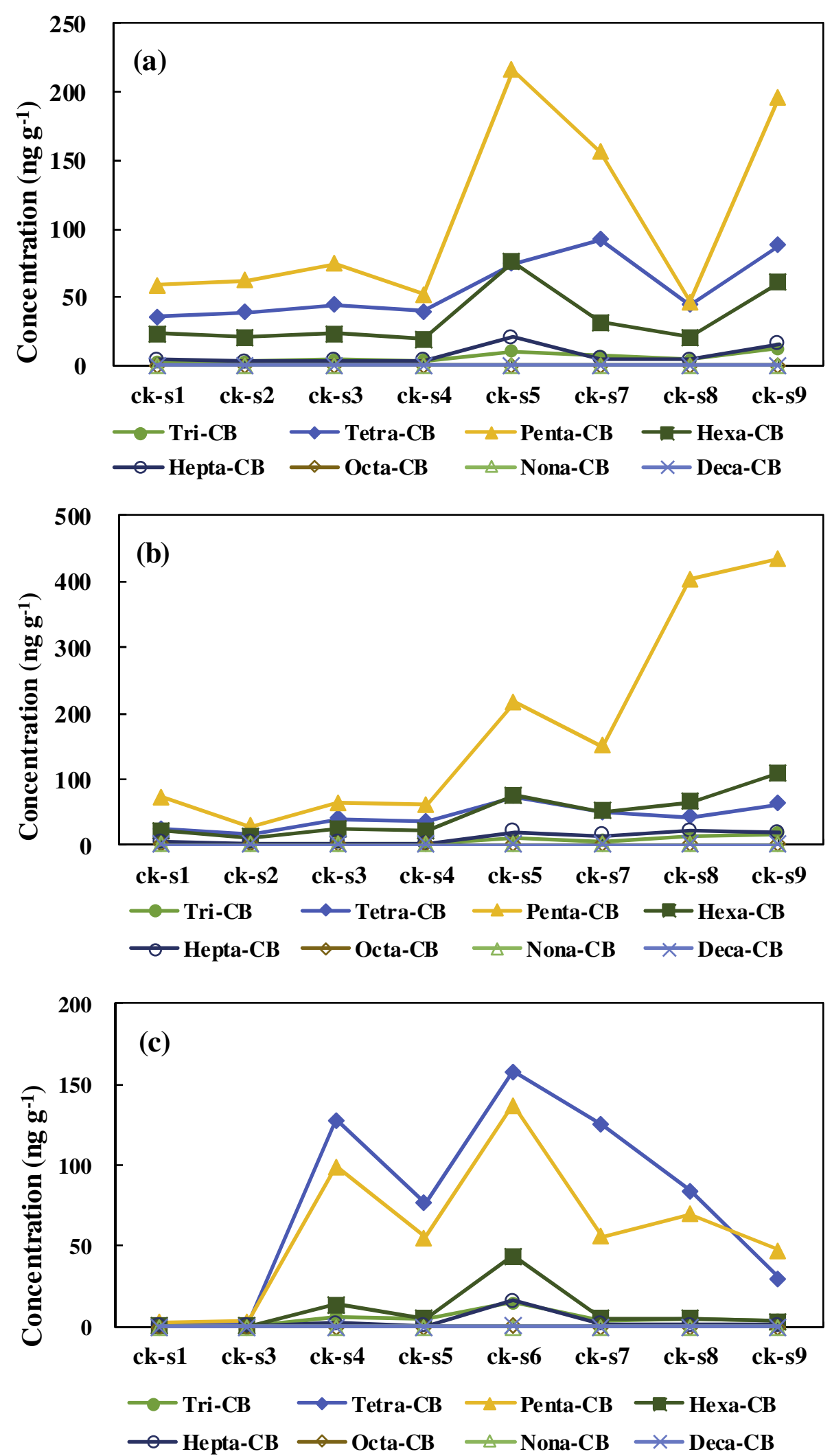

Fig. 5. Concentration of $P C B$ homologues for solid samples in Run 1 (a), Run 2 (b) and Run 3 (c).

et al. (2013).

The distributions of PCB homologues in the total input and output materials were also analyzed (Fig. 3c). The input and outputs in all three runs were dominated by tetra-to hexa-CB, which accounted for more than $90 \%$ of the total PCB mass. In Run 1 , the fraction of penta-CB decreased from $54.1 \%$ to $49.5 \%$ from input 
to output mass, while that of tetra-CB increased from $19.1 \%$ to $29.7 \%$. In Run 2, the penta-CB fraction decreased from $54.1 \%$ to $47.3 \%$ from input to output, while that of tetra-CB increased from $19.2 \%$ to $29.3 \%$. In Run 3, the tetra-CB fraction decreased from $52.2 \%$ to $32.3 \%$ from input to output, while that of penta-CB increased from $38.8 \%$ to $56.1 \%$. These changes could be evidence of the effect of cement kilns on PCB homologue distributions. We also calculated the reduction efficiencies for the PCB homologues. In Run 1 and Run 2, octa-CB (96.0\% and 99.3\%), and hepta-CB (88.8\% and $88.7 \%$ ) showed the highest reduction efficiencies among the homologues. Tetra-CB showed the lowest reduction efficiencies in Run 1 and Run 2 (64.5\% and $69.0 \%$, respectively), which could have caused the increase of the fraction of tetra-CB in the output. In Run 3, high reduction efficiencies were observed for all the homologues, and these reductions were not significantly different among the different runs. Overall, the reduction efficiencies for the higher chlorinated PCB homologues were higher than those for the lower chlorinated homologues.

For the three runs, the concentrations of PCB homologues in solid samples (Fig. 5) showed different trends for the PCB homologues. Similar to the trend observed for the input and output PCB homologue distribution, penta-CB and tetra-CB were the major homologues in almost all of the samples. This high fraction of penta-CB and tetra-CB appeared to originate from the raw meals used in Run 1 and Run 2, and raw meal, sewage sludge, and coal used in Run 3. The high concentration of penta-CB in the raw meals used in Run 1 and Run $2\left(216 \mathrm{pg} \mathrm{g}^{-1}\right)$, and corresponding high fractions (54.3\%) resulted in high concentrations of penta-CB in samples from the C1 preheater in Run 1 and Run 2 (156 and $151 \mathrm{pg} \mathrm{g}^{-1}$, respectively). This is evidence of the influence of raw meal on samples from the $\mathrm{C} 1$ preheater.

\section{Conclusions}

In the present study, samples collected from three cement production runs were analyzed to clarify $\mathrm{PCB}$ emission with sewage sludge co-processing. The dl-PCB concentrations and corresponding TEQs of stack gas were calculated, and showed that coprocessing of waste in cement kilns would not increase the emission of PCBs through stack gas. Raw meal was the major input sources of PCBs, while clinkers were the major output source of PCBs. Net emission calculations for the three runs indicated that the cement kilns would decrease the emission of dl-PCBs. Higher PCB concentrations were found in samples from the kiln end and $\mathrm{C} 1$ preheater than in samples from kiln head. CB-77, CB-105 and CB118 were the major dl-PCB congeners, and CB-52, CB-101 were the major indicator $\mathrm{PCB}$ congeners in all the solid samples. Congener analysis of the dl-PCBs and indicator PCBs that arose from cement kiln co-processing of sewage sludge showed that the unique $\mathrm{PCB}$ profiles could be used for $\mathrm{PCB}$ source analysis and discrimination from other industrial processes. Tetra- $C B$ to hexa-CB were the major homologues for the solid samples.

\section{Acknowledgements}

We gratefully acknowledge supports from the National 973 program (2015CB453100), the Chinese National Natural Science Foundation (91543108), and the Strategic Priority Research Program of the Chinese Academy of Sciences (XDB14020100) and Youth Innovation Promotion Association of the Chinese Academy of Sciences (2016038).

\section{References}

Ahlborg, U.G., Brouwer, A., Fingerhut, M.A., Jacobson, J.L., Jacobson, S.W.,
Kennedy, S.W., Kettrup, A.A.F., Koeman, J.H., Poiger, H., Rappe, C., Safe, S.H., Seegal, R.F., Tuomisto, J., Vandenberg, M., 1992. Impact of polychlorinated dibenzo-p-dioxins, dibenzofurans, and biphenyls on human and environmental-health, with special emphasis on application of the toxic equivalency factor concept. Eur. J. Pharmacol. Environmental Toxicol. Pharmacol. Sect. 228, 179-199.

Aranda Usón, A., López-Sabirón, A.M., Ferreira, G., Llera Sastresa, E., 2013. Uses of alternative fuels and raw materials in the cement industry as sustainable waste management options. Renew. Sust. Energ. Rev. 23, 242-260.

Blanchard, M., Teil, M.J., Ollivon, D., Legenti, L., Chevreuil, M., 2004. Polycyclic aromatic hydrocarbons and polychlorobiphenyls in wastewaters and sewage sludges from the Paris area (France). Environ. Res. 95, 184-197.

Conesa, J.A., Galvez, A., Mateos, F., Martin-Gullon, I., Font, R., 2008. Organic and inorganic pollutants from cement kiln stack feeding alternative fuels. J. Hazard. Mater. 158, 585-592.

Conesa, J.A., Rey, L., Egea, S., Rey, M.D., 2011. Pollutant formation and emissions from cement kiln stack using a solid recovered fuel from municipal solid waste. Environ. Sci. Technol. 45, 5878-5884.

Dang, J., Shi, X., Zhang, Q., Wang, W., 2015. Theoretical perspectives on the mechanism and kinetics of the OH radical-initiated gas-phase oxidation of PCB126 in the atmosphere. Sci. Total Environ. 517, 1-9.

Giesy, J.P., Kannan, K., 1998. Dioxin-like and non-dioxin-like toxic effects of polychlorinated biphenyls (PCBs): implications for risk assessment. Crit. Rev. Toxicol. 28, 511-569.

Guo, L., Zhang, B., Xiao, K., Zhang, Q., Zheng, M., 2009. Levels and distributions of polychlorinated biphenyls in sewage sludge of urban wastewater treatment plants. J. Environ. Sci. 21, 468-473.

Harrison, E.Z., Oakes, S.R., Hysell, M., Hay, A., 2006. Organic chemicals in sewage sludges. Sci. Total Environ. 367, 481-497.

Hu, J.C., Zheng, M.H., Nie, Z.Q., Liu, W.B., Liu, G.R., Zhang, B., Xiao, K., 2013. Polychlorinated dibenzo-p-dioxin and dibenzofuran and polychlorinated biphenyl emissions from different smelting stages in secondary copper metallurgy. Chemosphere 90, 89-94.

Jansson, S., Andersson, P.L., 2012. Relationships between congener distribution patterns of PCDDs, PCDFs, PCNs, PCBs, PCBzs and PCPhs formed during flue gas cooling. Sci. Total Environ. 416, 269-275.

Jiang, X., Liu, G., Wang, M., Zheng, M., 2015. Formation of polychlorinated biphenyls on secondary copper production fly ash: mechanistic aspects and correlation to other persistent organic pollutants. Sci. Rep. 5, 13903.

Jin, R., Zhan, J.Y., Liu, G.R., Zhao, Y.Y., Zheng, M.H., 2016. Variations and factors that influence the formation of polychlorinated naphthalenes in cement kilns coprocessing solid waste. J. Hazard. Mater. 315, 117-125.

Liu, G., Zhan, J., Zhao, Y., Li, L., Jiang, X., Fu, J., Li, C., Zheng, M., 2016. Distributions, profiles and formation mechanisms of polychlorinated naphthalenes in cement kilns co-processing municipal waste incinerator fly ash. Chemosphere 155 $348-357$.

Liu, G.R., Zhan, J.Y., Zheng, M.H., Li, L., Li, C.P., Jiang, X.X., Wang, M., Zhao, Y.Y., Jin, R., 2015. Field pilot study on emissions, formations and distributions of PCDD/Fs from cement kiln co-processing fly ash from municipal solid waste incinerations. J. Hazard. Mater. 299, 471-478.

Liu, G.R., Zheng, M.H., Ba, T., Liu, W.B., Guo, L., 2009. A preliminary investigation on emission of polychlorinated dibenzo-p-dioxins/dibenzofurans and dioxin-like polychlorinated biphenyls from coke plants in China. Chemosphere 75, 692-695.

Liu, G.R., Zheng, M.H., Cai, M.W., Nie, Z.Q., Zhang, B., Liu, W.B., Du, B., Dong, S.J., Hu, J.C., Xiao, K., 2013. Atmospheric emission of polychlorinated biphenyls from multiple industrial thermal processes. Chemosphere 90, 2453-2460.

Liu, G.R., Zheng, M.H., Nie, Z.Q., Li, C., Zhang, B., Liu, W.B., Hu, J.C., 2011. Characterizing the emission of polychlorinated naphthalenes from cement kiln. Organohalogen Compd. 73, 62-65.

Lv, P., Zheng, M.H., Liu, W.B., Zhang, B., Liu, G.R., Su, G.J., Nie, Z.Q., 2011. Estimation of emissions of polychlorinated dibenzo-p-dioxins and dibenzofurans and dioxinlike polychlorinated biphenyls from chinese hot dip galvanizing industries. Environ. Eng. Sci. 28, 671-676.

Nomiyama, K., Hirakawa, S., Eguch, A., Kanbara, C., Imaeda, D., Yoo, J., Kunisue, T., Kim, E.Y., Iwata, H., Tanabe, S., 2014. Toxicological assessment of polychlorinated biphenyls and their metabolites in the liver of baikal seal (Pusa sibirica). Environ. Sci. Technol. 48, 13530-13539.

Ozcan, S., Tor, A., Aydin, M.E., 2013. Investigation on the levels of heavy metals, polycyclic aromatic hydrocarbons, and polychlorinated biphenyls in sewage sludge samples and ecotoxicological testing. Clean-Soil Air Water 41, 411-418.

Pekárek, V., Weber, R., Grabic, R., Šolcová, O., Fišerová, E., Šyc, M., Karban, J., 2007. Matrix effects on the de novo synthesis of polychlorinated dibenzo-p-dioxins, dibenzofurans, biphenyls and benzenes. Chemosphere 68, 51-61.

Rivera-Austrui, J., Martinez, K., Marco-Almagro, L., Abalos, M., Abad, E., 2014. Longterm sampling of dioxin-like substances from a clinker kiln stack using alternative fuels. Sci. Total Environ. 485-486, 528-533.

Rovira, J., Mari, M., Nadal, M., Schuhmacher, M., Domingo, J.L., 2011. Use of sewage sludge as secondary fuel in a cement plant: human health risks. Environ. Int. 37, 105-111.

Rovira, J., Nadal, M., Schuhmacher, M., Domingo, J.L., 2014. Environmental levels of $\mathrm{PCDD} /$ Fs and metals around a cement plant in Catalonia, Spain, before and after alternative fuel implementation. Assessment of human health risks. Sci. Total Environ. 485-486, 121-129.

Safe, S., 1993. Toxicology, structure-function relationship, and human and 
environmental-health impacts of polychlorinated-biphenyls - progress and problems. Environ. Health Perspect. 100, 259-268.

Schuhmacher, M., Nadal, M., Domingo, J.L., 2009. Environmental monitoring of PCDD/Fs and metals in the vicinity of a cement plant after using sewage sludge as a secondary fuel. Chemosphere 74, 1502-1508.

Tuan, Y.J., Wang, H.P., Chang, J.E., 2012. Formation of PCDD/Fs in the cooling down process of incineration flue gas. Aerosol Air Qual. Res. 12, 1309-1314.

Van den Berg, M., Birnbaum, L.S., Denison, M., De Vito, M., Farland, W., Feeley, M., Fiedler, H., Hakansson, H., Hanberg, A., Haws, L., Rose, M., Safe, S., Schrenk, D. Tohyama, C., Tritscher, A., Tuomisto, J., Tysklind, M., Walker, N., Peterson, R.E. 2006. The 2005 World Health Organization reevaluation of human and mammalian toxic equivalency factors for dioxins and dioxin-like compounds.
Toxicol. Sci. 93, 223-241.

Weber, R., Iino, F., Imagawa, T., Takeuchi, M., Sakurai, T., Sadakata, M., 2001. Formation of PCDF, PCDD, PCB, and PCN in de novo synthesis from PAH: mechanistic aspects and correlation to fluidized bed incinerators. Chemosphere 44 1429-1438.

Werle, S., Wilk, R.K., 2010. A review of methods for the thermal utilization of sewage sludge: the polish perspective. Renew. Energy 35, 1914-1919.

Zhang, Q., Gao, R., Xu, F., Zhou, Q., Jiang, G., Wang, T., Chen, J., Hu, J., Jiang, W. Wang, W., 2014. Role of water molecule in the gas-phase formation process of nitrated polycyclic aromatic hydrocarbons in the atmosphere: a computational study. Environ. Sci. Technol. 48, 5051-5057. 